\title{
KAJIAN METODOLOGI SISTEM PRODUK SERVIS
}

\section{Devanny Gumulya ${ }^{1}$ dan Ernest Irwandi ${ }^{2}$}

\author{
Dosen Program Studi Desain Produk, \\ Universitas Pelita Harapan, Lippo Karawaci, Tangerang \\ devanny.gumulya@uph.edu ${ }^{1}$, ernest.irwandi@uph.edu ${ }^{2}$
}

\begin{abstract}
Abstrak
Perkembangan teknologi dan kemampuan produksi negara - negara berkembang berdampak pada persaingan harga produksi yang kompetitif. Beberapa negara maju seperti Jepang, Amerika Serikat, dan negara - negara di Eropa sudah tidak bisa bersaing harga produksi dengan negara berkembang maka sejak tahun 1970an mulai menggeser paradigma mereka pada ekonomi servis yang fokus pada memberikan pelayanan dan pengalaman terbaik pada konsumen. Akhirnya pada tahun 1990an, perusahaan manufaktur mulai merubah paradigma berpikirnya untuk menggabungkan produk dan servis menjadi solusi nilai yang ditawarkan pada konsumen inilah yang disebut sebagai sistem produk servis (SPS). Uber®, Grab®, Gojek® adalah contoh SPS yang berhasil diterima masyarakat. Untuk mengintegrasikan produk dan servis diperlukan metode dan perubahan cara pandang organisasi. Melihat pentingnya sebuah metode dalam SPS, hal ini sudah sering menjadi topik penelitian para peneliti. Oleh karena itu, di paper ini dikaji macam macam metode SPS yang ada saat ini. Dari studi ini didapatkan, bahwa dibutuhkan keseimbangan antara peneliti dan praktisi industri dari sejak awal. Hasil dari kajian ini adalah enam metode perancangan SPS yaitu : analisa kebutuhan customer, analisa studi kasus SPS, analisa SWOT, konsep SPS, flowchart SPS dan rincian dana untuk realisasi SPS
\end{abstract}

Kata kunci : Metodologi, Sistem Produk Servis

\begin{abstract}
As a result of the technology and manufacturability enhancement in developing countries, many countries like Japan United States and European countries have lost their competitive advantages. Since 1970s they move to service economy, in which experience from service excellence become important factor. In 1990s, manufacturer companies starts increasingly integrating products and services into innovative offerings, which create more values to customers, this is called product service system (PSS). Uber ${ }^{\circledR}$, Grab $^{\circledR}$, Gojek $^{\circledR}$ are the example of successful PSS application in transportation sector. To integrate services, in their core products, and to support this, process organizational changes are required, and a variety of methodologies that integrate the product and services development processes are needed. This topic has been researched for several years. This paper aims to identify state of the art PSS methodology. It will focus on the advantages and disadvantages, their objectives, the proposed tools/methods and the elements used in the tools, as well as the challenges. From the study founded that to enhance the industrial applicability of the PSS methodologies, collaboration between researchers and practitioners have to be emphasized through all the PSS approach. From the study founded there are 6 methods for designing PSS : consumer need analysis, PSS study case analysis, SWOT analysis, PSS concept, PSS flowchart and financial plan for PSS realization.
\end{abstract}

Keywods : product service system, methodology 


\section{PENDAHULUAN}

Globalisasi, perkembangan teknologi dan pembangunan di negara negara berkembang mendukung mereka menjadi negara manufaktur. Negara maju seperti Jepang, Inggris, Jerman sudah tidak bisa bersaing harga manufaktur dengan negara berkembang, maka sejak tahun 1970an mulai menggeser paradigma mereka pada ekonomi servis yang fokus pada memberikan pelayanan dan pengalaman terbaik pada konsumen (Berkowitz, 1987, Bloch, 1995, Bouchenoire, 2003, Kreuzbauer, Malter 2005). Akhirnya pada tahun 1990an muncul konsep yang menggabungkan produk dan servis menjadi solusi nilai yang ditawarkan pada konsumen inilah yang disebut sebagai system produk servis (SPS). Uber ${ }^{\circledR}$, Grab $^{\circledR}$, Gojek $^{\circledR}$ adalah contoh SPS yang berhasil diterima masyarakat. Uber ${ }^{\circledR}$ menawarkan solusi transportasi, perbedaannya dengan taksi biasa adalah dengan konsep Uber ${ }^{\circledR}$ semua yang memiliki mobil bisa menawarkan jasa transportasi. Keunikan SPS adalah multistakeholder terlibat menawarkan solusi produk servis. Dengan multistakeholder saling bekerja sama, maka kepemilikan produk dan optimisasi penggunaan produk dapat ditingkatkan. Karena, sifatnya yang mengurangi pembuatan dan optimisasi kegunaan produk, maka SPS memiliki potensi untuk menjadikan bisnis lebih ramah lingkungan.

Sistem produk servis (Product Service System - SPS) tergolong baru dan belum dipahami masyarakat awam. Penelitian tentang metode bagaimana mengaplikasikan konsep SPS juga masih sangat terbatas terutama di Indonesia, padahal SPS memiliki potensi agar sebuah bisnis dapat menjadi lebih kompetitif di pasar dan dapat mengarahkan bisnis ke arah ramah lingkungan karena fokusnya pada value bukan pada kepemilikan produk.

Pertanyaan yang mau dijawab kajian ini :

1. Bagaimana proses desain dari SPS ?

2. Bagaimana metode desain yang dapat diaplikasikan dalam proses desain SPS ?

Tujuan kajian ini adalah untuk membuka wawasan umum tentang SPS, selama ini kita sudah akrab dengan solusinya tapi belum memahami proses bagaimana menghasilkan solusi SPS. Saat ini Indonesia masih dapat bersaing harga manufaktur dengan negara berkembang lainnya, tapi tidak ada salahnya bila kita sudah memulai memikirkan kedepan, karena menurut data dari kementrian pertahanan Inggris di tahun 2005, konsumen akan lebih tertarik membeli nilai dari dari produk fisik.

\section{TINJAUAN PUSTAKA}

Menurut Manzini \& Vezzoli (2000) dan Mont (2002), sistem produk servis (SPS) adalah sebuah konsep inovasi strategi yang merubah arah focus bisnis dari menjual produk menjadi menjual nilai integrasi dari produk dan servis untuk memenuhi kebutuhan customer dengan dampak pada lingkungan yang rendah. Menurut Meier (2010), SPS adalah konsep bisnis yang menawarkan integrasi produk dan sevis dalam satu sistem sebagai solusi bagi customer. Tujuan intregasi ini adalah untuk mengoptimasi siklus hidup sebuah produk dari kacamata customer. Menurut Tukker dan Tischner (2008), Dengan konsep SPS sebuah bisnis dapat diarahkan ke srategi menuju sustainabilitas dengan efisiensi sumber, penggunaan energi dan mengurangi pencemaran lingkungan. Konsep SPS dapat mengarahkan bisnis kearah sustainabilitas dengan memperbanyak penggunaan produk oleh banyak orang, 
yang sebelumnya produk hanya dimiliki secara individual (Ramirez, 2016).

Konsep SPS bisa hadir karena beberapa fakor, pertama untuk menjawab tantangan krisis ekonomi yang terjadi di Eropa tahun 1990an, dimana untuk melakukan inovasi produk biaya yang diperlukan mahal, maka arahan ekonomi berubah kearah inovasi servis. Akhirnya mulai muncul pemikiran untuk menggabungkan konsep produk dan servis di Eropa. Di sisi lain, isu lingkungan juga mendorong munculnya konsep SPS, konsumerisme yang berlebihan mendorong orang untuk terus membeli produk yang akhirnya menjadi sampah lingkungan yang tidak bisa didaur ulang. Hal ini mendorong pemikiran mengapa orang harus membeli produk? padahal yang dibutuhkan adalah nilai dari produk tersebut, apakah produk itu bisa dibagi kegunaannya dengan banyak orang. Output dari SPS tidak secara langsung pasti menjadi solusi desain yang ramah lingkungan, tapi pada umumnya mereka memiliki potensi menuju kearah itu dan hasilnya perlu diverifikasi kasus per kasus. Pemikiran pemikiran ini mendorong munculnya konsep SPS, bahkan akhirnya menjadi cabang ilmu paska sarjana di Universitas Politecnico di Milano Italia.

\section{Tipe SPS}

Ada tiga tipe SPS yang umumnya diketahui di bidang riset desain (Baines et al., 2007; Tukker, 2004; Yang, Moore, $\mathrm{Pu}, \&$ Wong, 2009) : SPS berorientasi pada hasil, SPS berorientasi pada kegunaan, SPS berorientasi pada produk

1. SPS berorientasi pada hasil

Konsep SPS berorientasi hasil adalah konsep bisnis dimana perusahaan menjual hasil akhir atau nilai dari produk bukan fisik/produknya yang dijual. Jadi pembeli membayar per pemakaian. Hak kepemilikan produk tetap ada di perusahaan, yang bertanggung jawab hal perawatan dan daur ulang produk.

2. SPS berorientasi pada kegunaan

Konsep SPS berorientasi kegunaan adalah perusahaan menyewakan/membagi produk kepada satu atau beberapa pembeli (Tukker, 2004). Misalnya pembeli menyewa peralatan yang sifat pemakaiannya non rutin seperti bertaman, atau renovasi rumah dsb. Perusahaan membuat infrastruktur agar produk dapat diakses pembeli dengan mudah untuk proses pengambilan, pengembalian produk dan pembayaran jasa produk.

3. SPS berorientasi pada produk

Konsep SPS berorientasi produk adalah perusahaan menjual produk dan hak kepemilikan berpindah ke tangan pembeli. Servis garansi diberikan untuk menjamin fungsi dan durabilitas produk (Baines et al., 2007). Misalnya perusahaan menawarkan jasa after sales service atau servis konsultasi cara pengoperasian produk (Tukker, 2004).

Menurut Manzini (2011) agar konsep SPS berjalan dengan baik beberapa faktor harus diperhatikan seperti keunikan nilai (unique value), target konsumen, ketepatan tipe SPS dengan target market, produk dan servis ditawarkan sebagai satu solusi integratif pemenuhan konsumen. Menurut Vasantha et al. (2012) dan Mont (2002) kolaborasi antara stakeholder dinilai sebagai aspek yang penting agar sebuah SPS dalam berjalan dengan baik dan hubungan antara supplier dan pengembang menjadi hal yang penting dalam pengembangan konsep SPS.

\section{Studi Metodologi SPS}

Pada dasarnya produk dan servis memiliki proses pengembangannya 
sendiri - sendiri. Ulrich dan Eppinger (2007) mengusulkan proses pengembangan produk baru secara berurut yaitu: perencanaan, pengembangan konsep, detail desain, pengujian dan perbaikan, proses produksi. Scheuing dan Johnsoon (1989) mengusulkan empat tahapan pengembangan servis baru yaitu: penentuan arah, proses desain, proses pengujian dan pengenalan. Pengembangan SPS tidak dapat menggunakan arahan ini karena SPS bukan hanya perkembangan produk dan servis tapi integrasi dari kedua hal ini.

Pada tahun 2005 riset bertema metodologi SPS disebut dengan metholodology for product service systems (MPESS). Ada lima tahapan dalam pengembangan SPS :

1. Tahap analisa strategi

2. Eksplorasi kebutuhan

3. Pengembangan ide SPS

4. Pengembangan SPS

5. Implementasi SPS

Kim (2014) mencoba mengintegrasikan kerangka pengembangan SPS berdasarkan risetnya pada proses pengembangan produk dan servis baru. Kerangka dibagi menjadi empat tahap. Tahap pertama desainer menganalisa kondisi internal dan eksternal produsen. Selanjutnya desainer memahami permasalahan yang dihadapi konsumen. Setelah memahami permasalahan produsen dan konsumen, SPS desainer mulai memikirkan ide berdasarkan informasi yang didapatkan sebelumnya. Ide SPS sebaiknya menjawab permasalahan konsumen dan produsen. Langkah selanjutnya adalah penjabaran detail dari ide SPS, produk dan servis apa yang ditawarkan, stakeholder apa yang terlibat, interaksinya bagaimana. Langkah terakhir adalah test SPS pada pasar, apakah ide SPS dapat diterima dengan baik.
Kajian ini membahas metodologi pengembangan SPS secara umum bukan untuk katagori bisnis tertentu. Berikut metode SPS yang umum digunakan

1. Flowchart SPS : Morelli $(2002,2006)$

Flowchart adalah diagram proses yang menjelaskan tahap demi tahap bagaimana sesuatu bekerja. Flowchart dalam konteks SPS sering digunakan sebagai metode untuk menjabarkan observasi dan kondisi yang ada. Selain untuk menunjukkan keadaaan saat ini. Flowchart juga sering dipakai untuk menarasikan bagaimana sebuah konsep SPS berjalan. Metode ini dimulai dengan menentukan stakeholder terlibat dalam SPS, tujuannya adalah untuk menentukan hal - hal yang dibutuhkan dari setiap stakeholder agar SPS berjalan. Di flowchart ini stakeholder, infrastruktur, lini interaksi antara customer dan produsen (pemilik konsep SPS), proses pendukung lainnya didefinisikan dengan jelas.

\section{Metode MPEPSS}

Means End Chain Analysis of Product Service System atau disebut MEPSS. Metode yang dikembangkan oleh Robert Wimmer (Wilma Aarts Gerd Scholl 2004) dalam hasil publikasi penelitiannya "Success and Failure Factors Methodology and Tool Testing" yang diinspirasikan dari model Gutman yaitu Means end Chain model (1982). Metode dibagi menjadi tiga tahapan yaitu :

a. Tahap Analisa Strategi:

Identifikasi dan Mapping
Stakeholders, pada tahap ini
semua stakeholder yang
terhubung dalam supply chain
sebuah unit usaha diidentifikasi
melalui sesi brainstorming,
Stakeholder dibagi menjadi


primer dan sekunder, sosial dan non sosial.

b. Tahap Eksplorasi

1) Identifikasi kebutuhan customer dan produsen

Analisa ini bertujuan untuk mengetahui hirarki kebutuhan konsumen dan mempertemukan keinginan konsumen dengan produsen dan melihat rantai kebutuhan konsumen dalam aspek:

a) Terminal Value

Nilai akhir yang diperoleh oleh konsumen atau merupakan kesimpulan akhir atas seluruh nilai dari sebuah produk.

b) Instrumental value

Suatu nilai yang diperoleh ketika produk dikenakan atau digunakan, atau produk digunakan sebagai alat untuk memperoleh sesuatu. Misalnya nilai instrumen dari menggunakan sebuah produk tertentu adalah: dapat meningkatkan harga diri (self esteem), status sosial atau penerimaan sosial.

c) Psychological needs Dampak emosional dari sebuah produk atau dampak perilaku ketika menggunakan sebuah produk, misalnya produk tertentu dibuat agar pemakaian produk digunakan secara aman.

d) Financial consequences Pertimbangan antara nilai fungsional dengan harga dari sebuah produk.

e) Abstract attributes

Karakteristik produk yang berhubungan dengan rasa (sense) atau efek terhadap indrawi, atau atribut yang berhubungan dengan pengalaman ketika menggunakan produk. Misalnya pada produk tertentu walau bentuk fisik besar namun terasa ringan ketika dibawa.

f) Concrete attributes

Karateristik fisik produk yang bersifat konkret dari ukuran, material atau spesifikasi sebuah produk.

2) Analisa SWOT dilakukan untuk mengetahui posisi unit usaha di pasar.

Pertanyaan yang perlu dijawab dari segi customer adalah :

a) Keunggulan unit usaha dari kompetitor lainnya dari segi harga, kualitas layanan, dan image.

b) Keberhasilan unit usaha mencapai segmen pasar.

c) Apakah unit usaha menyediakan solusi kustom bagi customer?

d) Apakah produk dan layanan unit usaha mudah ditiru competitor sejenis?

c. Tahap penyusunan konsep SPS System Map (Jaques et al, 2005)

Diagram yang mengilustrasikan bagaimana stakeholder saling terhubung agar SPS dapat berjalan. Interaksi antar stakeholder dibagi menjadi tiga : informasi, fisik dan finasial. 


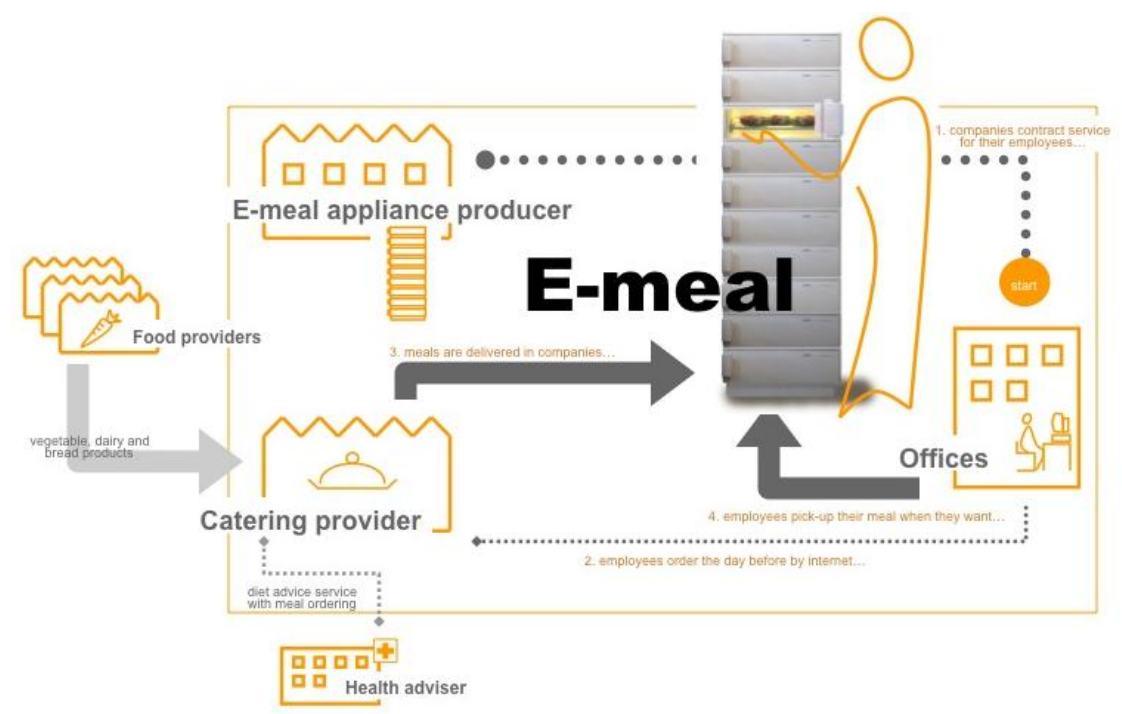

Gambar 1. Contoh System Map

Sumber : http://www.mepss.nl/index.php?p=tool\&14=W21

3. SPS ideation support system, Kim et. $\mathrm{al}(2014)$

Metode ini memiliki beberapa perangkat: tabel solusi model SPS, tabel analisa kebutuhan, dan Ideation support matrix (ISM). Pada dasarnya metode ingin mengarahkan desainer mencari ide SPS yang relevan dengan kebutuhan konsumen.

a. Tabel analisa kebutuhan

Identifikasi kebutuhan konsumen dengan wawancara. Hasil dari wawancara dirangkum dalam tabel. Tujuan disini adalah mencari kebutuhan umum yang dibutuhkan oleh banyak pihak.

b. Tabel solusi model SPS

Di tabel ini data semua studi kasus SPS yang bisa menjawab kebutuhan umum konsumen dicari dan dibahas. Semua studi kasus dicari kesamaan variabelnya. Contohnya berdasarkan studi kasus car sharing, sharing mainan lego, didapatkan variabel berbagi kegunaan produk, tidak digunakan oleh satu orang saja dan kedua variable ini menjadi satu deskripsi solusi modul SPS yaitu berbagi.

c. Ideation Support Matrix

Di tabel ini kedua variabel yang sudah ditemukan sebelumnya dihubungkan, bila studi kasus menjawab kebutuhan umum konsumen maka studi kasus diletakkan di kolom persimpangan solusi model SPS dan analisa kebutuhan. Jadi melalui tabel ini dapat dilihat bentuk model SPS yang paling menjawab kebutuhan konsumen. Studi kasus ini dapat dijadikan pegangan untuk pengembangan ide SPS yang baru. Desainer dapat melakukan brainstorming dengan tim untuk mengembangkan ide SPS 


\begin{tabular}{|c|c|c|c|c|c|}
\hline $\begin{array}{l}\text { PSS solution model } \\
\text { General needs }\end{array}$ & $\begin{array}{l}\text { Use pro-environmental } \\
\text { resources }\end{array}$ & Recycle service & $\begin{array}{c}\text { Diagnosis \& Analysis } \\
\text { service }\end{array}$ & $\begin{array}{c}\text { Information } \\
\text { providing service }\end{array}$ & Maintenance service \\
\hline \multicolumn{6}{|l|}{$\begin{array}{c}\text { Need of various } \\
\text { designs or functions }\end{array}$} \\
\hline $\begin{array}{c}\text { Need of pro- } \\
\text { environmental design }\end{array}$ & 277781 & & & & \\
\hline $\begin{array}{l}\text { Need of special function or } \\
\text { customized use }\end{array}$ & & & & & 37767786 \\
\hline $\begin{array}{l}\text { Need of less cost } \\
\text { to buy or use }\end{array}$ & & 1781 & & 90 & \\
\hline \multicolumn{6}{|l|}{ Need of simple buy } \\
\hline $\begin{array}{c}\text { Need of more information } \\
\text { over } \\
\text { life cycle }\end{array}$ & & & 24 & 3518390 & \\
\hline Need of optimized use & & & 53442436789 & 383 & $\begin{array}{c}256112831323758606567 \\
687686\end{array}$ \\
\hline Need of best performance & & & & 8392 & 67356077 \\
\hline
\end{tabular}

Tabel 2 1. Tabel Ideation Support Matrix (ISM)

Sumber :

https://www.researchgate.net/publication/228720468_A_Concept_Generation_Support_System_for_Prod uct-Service_System Development

\section{d. Konsep SPS}

Setiap ide SPS yang dihasilkan harus dijabarkan dengan detail sebagai berikut : 1) nama dari idenya 2) deskripsi singkat 3) masalah yang dipecahkan 4) target customer 5) apa yang ditawarkan 5) bagaimana cara menawarkannya 8) stakeholder yang terlibat dan 9) keuntungan. Dengan demikian dapat dihasilkan ide SPS yang benar benar menjawab masalah dan permasalahan konsumen.

\begin{tabular}{|c|c|}
\hline $\begin{array}{l}\text { Problems } \\
\text { - Standardized and not various washing } \\
\text { machines } \\
\text { - Concern with polluted river }\end{array}$ & $\begin{array}{l}\text { Target customers } \\
\text { - Customers who are sensitive with } \\
\text { environmental issues } \\
\text { - Customers who are interested with new } \\
\text { technology, such as early adopters }\end{array}$ \\
\hline $\begin{array}{l}\text { What to offer } \\
\text { - Provide washing machine with function or } \\
\text { device to make sewage clean } \\
\text { - Offer customized service and maintenance } \\
\text { service to discharge least pollution } \\
\text { - Monitoring service and diagnosis service is } \\
\text { also offered to analyze pollution }\end{array}$ & $\begin{array}{l}\text { How to offer } \\
\text { - No additional charge to the function or device } \\
\text { when washing machine is upgraded } \\
\text { - Maintaining the area } \\
\text { - Monitoring and diagnose through wireless } \\
\text { communication }\end{array}$ \\
\hline $\begin{array}{l}\text { Stakeholders } \\
\text { - Washing machine manufacturer } \\
\text { - Technology owner } \\
\text { - Customers } \\
\text { - Government or organizations concern } \\
\text { environmental issues }\end{array}$ & $\begin{array}{l}\text { Benefits } \\
\text { - Economical values added: high customer } \\
\text { loyalty, possible tax exemption, high entry } \\
\text { barrier } \\
\text { - Environmental \& social values added: } \\
\text { pollution decreases, pro-environmental } \\
\text { atmosphere of the society }\end{array}$ \\
\hline
\end{tabular}

Tabel 22 Deskripsi Konsep SPS

Sumber :

https://www.researchgate.net/publication/228720468_A_Concept_Generation_Support_System_for_Prod uct-Service_System_Development 
4. Metode SPS model bisnis, Barquet et al. (2013)

Ada 8 step mulai dari input hingga output. Tahapan mulai dari analisa SWOT, pemahaman bisnis model yang sudah dijalankan saat ini, segmentasi customer, nilai yang ditawarkan, hubungan dengan customer, penetapan stakeholder yang terlibat, sumber yang dibutuhkan, sumber dana, hingga perincian dana yang dibutuhkan solusi SPS.

5. Metode technical business, Peruzzi et al. (2015)

Metode yang menjabarkan mulai dari identifikasi kebutuhan dan keinginan customer, identifikasi asset yang dimiliki perusahaan, stakeholder yang terlibat dan bagaimana mentranslasikannya faktor - faktor ini menjadi kriteria SPS.

6. Metode perkembangan product service system, Marques et. al (2013) Dalam artikelnya yang berjudul "A methodology for product-service systems development" merumuskan tahap - tahap bagaimana menggabungkan produk dan servis dalam satu proses desain.

a. Tahap persiapan organisasi : review proses desain produk dan servis yang ada selama ini.

b. Tahap perencanaan (planning): tahap ini dibagi dua internal dan eksternal. Faktor eksternal: identifikasi kebutuhan (needs) dan permintaan (wants) yang ada di pasar. Nilai (value) apa yang dicari customer dari pembelian produk. Identifikasi dapat dilakukan dengan survei market melalui metode wawancara dengan pembeli secara langsung, pembagian kuisoner via online survey. Faktor internal dari badan usaha yang ingin mengembangkan SPS. Faktor-faktor yang harus dipertimbangkan: kemampuan produksi, identifikasi stakeholder yang terlibat dalam proses inputoutput produk. Hal - hal ini dibutuhkan untuk menstimulasi ide - ide PSS.

c. Tahap desain: tahap pengembangan konsep produk servis yang terintegrasi satu sama lain. Setelah mengetahui needs dan wants dari pasar, harus dianalisa nilai (value) apa yang dinginkan customer ketika membeli produk, apakah faktor fungsi, hasil akhir, atau kepemilikan, hal ini perlu diketahui untuk menentukan tipe PSS . Setelah tipe PSS diketahui maka konsep yang dikembangkan akan lebih jelas. Output tahap desain adalah prototipe rancangan produk dan servis yang umumnya divisualisasikan dengan produk dan video yang menggambarkan scenario PSS.

d. Tahap implementasi : penjabaran bagian mana yang harus dikerjakan per divisi, bagian mana yang dapat dikerjakan sendiri dan bagian mana yang harus dikerjakan orang lain (outsource)

\section{Proses Desain}

Pada dasarnya walaupun SPS adalah perancangan strategi desain, tapi SPS tetap masuk dalam konteks proses desain. Sebelum memahami bagaimana aplikasi SPS dalam proses desain, perlu dipahami proses desain yang umum digunakan oleh industri. Beberapa alur proses desain yang umum digunakan di perusahaan manufaktur desain. Proses desain hasil penelitian desain council Inggris pada beberapa perusahaan desain tahun 2005. 


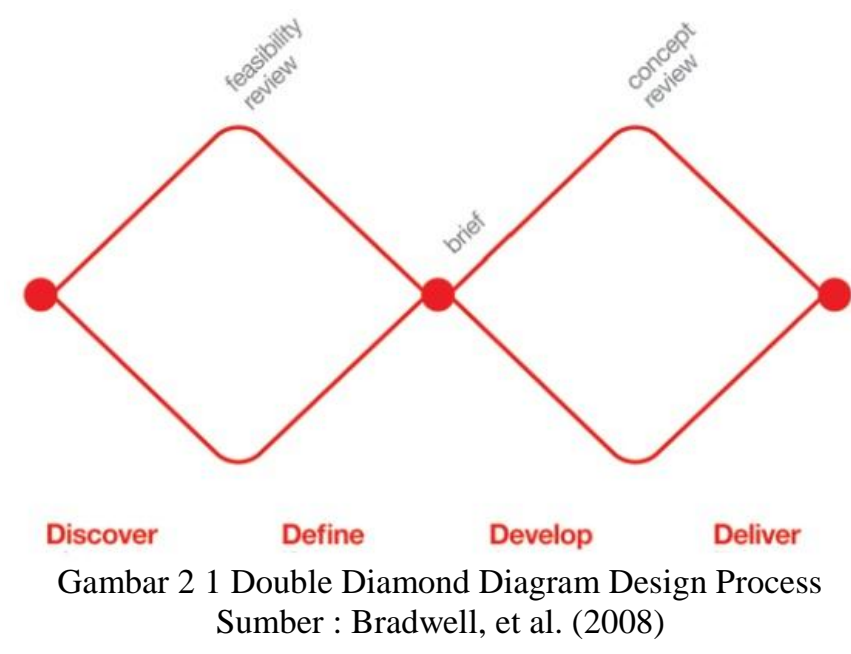

Diagram ini terbagi dalam 4 fase yaitu, discover, define, develop dan deliver.

Discover: Tahap awal dari proses desain yaitu pencarian ide, inspirasi, identifikasi kebutuhan target pasar dan juga arah tren desain dalam kurun waktu $3-5$ tahun mendatang. Pada tahap ini perusahaan harus berpikiran terbuka agar dapat mengidentifikasi masalah ataupun peluang kebutuhan baru yang ada di pasar. Fase ini diakhiri dengan penjabaran masalah ataupun peluang yang ada dipasar yang dapat dijadikan proyek desain.

Define: Pada tahap ini semua ide dan data dianalisa dan disintesi menurut kepentingan bisnis perusahaan. Pimpinan perusahaan memberikan batasan batasan konsep desain baik itu dari segi teknologi, biaya, sumber daya, dan lainlain. Dengan referensi data - data yang sudah diseleksi, penjabaran pengembangan proyek desain (design brief) dibuat. Di akhir tahap ini, masalah yang ingin dipecahkan dan strategi untuk memecahkan masalah melalui desain sudah jelas dan disetujui oleh pimpinan perusahaan. Beberapa perusahaan yang menjadi objek penelitian Design Council menyebutkan bahwa fase discover dan define dari proses desain sangat penting dan memiliki kontribusi besar pada kesuksesan hasil desain akhir.

Develop: Pada tahap ini tim desain secara mandiri atau bersama divisi lain di perusahaan seperti engineering dan pemasaran mengembangkan satu atau lebih konsep desain yang menjawab masalah yang diidentifikasi pada tahap sebelumnya. Metode pengembangan desain yang umumnya digunakan disini adalah metode kreatif seperti brainstorming, visualisasi, prototipe, dan uji coba. Di akhir tahap ini, desain sudah siap dikirim ke bagian produksi.

Deliver: Tahap akhir dimana desain sudah diproduksi, lulus tes akhir dan siap untuk diluncurkan di pasar. Setelah produk diperkenalkan di pasar, tes feedback dari pasar juga dilakukan untuk mengetahui apakah produk berhasil di pasaran.

\section{HASIL PENELITIAN DAN PEMBAHASAN}

Metode yang digunakan dalam kajian ini adalah studi literatur jurnal dengan pendekatan kualitatif. Lima belas jurnal dari tahun 2002-2014 bertema metodologi SPS dikaji dan dicari deskripsi tahapan dan perangkat yang dibutuhkan untuk pengembangan SPS. Setelah memahami masing - masing 
metode dianalisa variable penting dari setiap metode relevansinya dengan proses desain double diamond diagram.

\begin{tabular}{|c|c|c|c|c|}
\hline No. & Referensi & Metode & Kelebihan & Kekurangan \\
\hline 1 & $\begin{array}{l}\text { Morelli } \\
(2002,2006)\end{array}$ & Flowchart SPS & $\begin{array}{lr}\text { Menjelaskan } & \\
\text { dengan } & \text { detail } \\
\text { bagaimana } & \text { SPS } \\
\text { bejalan } & \end{array}$ & $\begin{array}{l}\text { Tidak } \\
\text { menjelaskan } \\
\text { tahapan yang } \\
\text { perlu dilakukan } \\
\text { sebelum } \\
\text { menyusun } \\
\text { flowchart SPS }\end{array}$ \\
\hline 2 & $\begin{array}{ll}\text { Robert Wimmer } \\
\text { (2004) } & \text { Manzini } \\
\text { and } & \text { Vezzoli, } \\
2011 & \end{array}$ & MPESS & $\begin{array}{l}\text { Menjelaskan } \\
\text { dengan detail tahap } \\
\text { - tahap dan } \\
\text { instrument yang } \\
\text { dibutuhkan untuk } \\
\text { SPS }\end{array}$ & $\begin{array}{l}\text { Butuh tim besar } \\
\text { untuk mengulik } \\
\text { metode ini }\end{array}$ \\
\hline 3 & $\begin{array}{l}\text { Kim et. al } \\
(2014)\end{array}$ & $\begin{array}{l}\text { SPS ideation } \\
\text { support system, }\end{array}$ & $\begin{array}{l}\text { Membantu desainer } \\
\text { untuk } \\
\text { menghubungkan } \\
\text { kebutuhan pasar } \\
\text { dan ide SPS }\end{array}$ & $\begin{array}{l}\text { Penjabaran detail } \\
\text { realisasi SPS } \\
\text { tidak dijelaskan }\end{array}$ \\
\hline 4 & $\begin{array}{l}\text { Barquet et al. } \\
\text { (2013) }\end{array}$ & $\begin{array}{l}\text { Metode SPS model } \\
\text { bisnis }\end{array}$ & $\begin{array}{lr}\text { Menyusun } & \text { konsep } \\
\text { SPS } & \text { sebagai } \\
\text { perancangan bisnis }\end{array}$ & $\begin{array}{l}\text { Harus ada } \\
\text { landasan konsep } \\
\text { bisnis } \\
\text { sebelumnya, } \\
\text { karena metode ini } \\
\text { cocok untuk } \\
\text { mengembangkan } \\
\text { konsep bisnis } \\
\text { konvensional } \\
\text { menjadi SPS }\end{array}$ \\
\hline 5 & $\begin{array}{l}\text { Peruzzini et al. } \\
(2015)\end{array}$ & $\begin{array}{l}\text { Metode Technical } \\
\text { Business }\end{array}$ & $\begin{array}{l}\text { Membantu desainer } \\
\text { untuk } \\
\text { menghasilkan ide } \\
\text { secara terstruktur } \\
\text { dan realistis }\end{array}$ & $\begin{array}{l}\text { Harus ada } \\
\text { landasan konsep } \\
\text { bisnis } \\
\text { sebelumnya, } \\
\text { karena metode ini } \\
\text { cocok untuk } \\
\text { mengembangkan } \\
\text { konsep bisnis } \\
\text { konvensional } \\
\text { menjadi SPS }\end{array}$ \\
\hline 6 & $\begin{array}{l}\text { Marques et. al } \\
(2013)\end{array}$ & $\begin{array}{l}\text { Metode } \\
\text { perkembangan } \\
\text { product service } \\
\text { system }\end{array}$ & $\begin{array}{l}\text { Menjabarkan secara } \\
\text { detail proses } \\
\text { pengembangan ide } \\
\text { SPS }\end{array}$ & $\begin{array}{l}\text { Tahapan desain } \\
\text { tidak } \\
\text { menjelaskan } \\
\text { bagaimana } \\
\text { mengintegrasikan } \\
\text { produk dan servis }\end{array}$ \\
\hline
\end{tabular}

Keenam metode yang sudah dideskripsikan sebelumnya dikaji 
Dari keenam metode ini diambil perangkat - perangkat SPS yang bisa diaplikasikan dalam proses desain.

\begin{tabular}{|c|c|c|c|c|c|c|c|c|}
\hline No & $\begin{array}{l}\text { Perangkat } \\
\text { SPS/ } \\
\text { Proses } \\
\text { desain } \\
\text { double } \\
\text { diamond } \\
\text { diagram }\end{array}$ & $\begin{array}{l}\text { Analisa } \\
\text { kebutuh } \\
\text { an } \\
\text { custome } \\
\text { r }\end{array}$ & $\begin{array}{l}\text { Anali } \\
\text { sa } \\
\text { studi } \\
\text { kasus } \\
\text { SPS }\end{array}$ & $\begin{array}{l}\text { Analisa } \\
\text { stakehol } \\
\text { der }\end{array}$ & $\begin{array}{l}\text { Anali } \\
\text { sa } \\
\text { SWO } \\
\text { T }\end{array}$ & $\begin{array}{l}\text { Kons } \\
\text { ep } \\
\text { SPS }\end{array}$ & $\begin{array}{l}\text { Syste } \\
\text { m } \\
\text { Map } \\
\text { SPS }\end{array}$ & $\begin{array}{l}\text { Rincia } \\
\text { n dana } \\
\text { untuk } \\
\text { realias } \\
\text { asi SPS }\end{array}$ \\
\hline 1 & $\begin{array}{l}\text { Discover : } \\
\text { pencarian } \\
\text { ide dan } \\
\text { identifikas } \\
\text { i } \\
\text { kebutuhan } \\
\text { pasar }\end{array}$ & $\mathbf{X}$ & $\mathbf{X}$ & $\mathbf{X}$ & & & & \\
\hline 2 & $\begin{array}{l}\text { Define : } \\
\text { analisa } \\
\text { data dan } \\
\text { identifikas } \\
\text { i masalah }\end{array}$ & & & & $\mathbf{X}$ & & & \\
\hline 3 & $\begin{array}{l}\text { Develop : } \\
\text { pengemba } \\
\text { ngan } \\
\text { konsep } \\
\text { desain }\end{array}$ & & & & & $\mathbf{X}$ & & \\
\hline 4 & $\begin{array}{l}\text { Deliver : } \\
\text { pembuatan } \\
\text { desain }\end{array}$ & & & & & & $\mathbf{X}$ & $\mathbf{X}$ \\
\hline
\end{tabular}

1. Analisa kebutuhan customer : menggabungkan metode Robert Wimmer (2004) dan Kim et. al (2014). Dengan menganalisa kebutuhan nilai akhir, kegunan, psikologi, finansial, abstrak dan fisik produk dari konsumen dapat diambil beberapa kebutuhan umum yang dibutuhkan konsumen.

2. Analisa studi kasus SPS dari Kim et. al (2014) : semua studi kasus SPS yang bisa menjawab kebutuhan umum konsumen dicari dan dibahas. Studi - studi kasus dicari kesamaan variabelnya.

3. Analisa stakeholder: banyak digunakan tiga dari enam metode SPS. Karena solusi SPS umumnya melibatkan banyak stakeholder, maka identifikasi stakeholder sangat penting untuk dilakukan

4. Analisa SWOT : untuk mengetahui posisi unit produsen di pasar

5. Konsep SPS dijabarkan dengan mengunakan pendekatan Kim et. al (2014). Setiap ide SPS yang dihasilkan harus dijabarkan dengan detail sebagai berikut : 1) nama dari idenya 2) deskripsi singkat 3) masalah yang dipecahkan 4) target customer 5) apa yang ditawarkan 5) bagaimana cara menawarkannya 8) stakeholder yang terlibat dan 9) keuntungan. Dengan demikian dapat dihasilkan ide SPS yang benar - benar menjawab 
masalah dan permasalahan konsumen.

6. System Map SPS : Setelah konsep dijabarkan dan stakeholder sudah teridentifikasi maka dibuat diagram untuk menarasikan bagaimana semua stakeholder saling terlibat hingga sebuah konsep SPS berjalan.Interaksi antar stakeholder dibagi menjadi tiga : informasi, fisik dan finasial.

7. Metode ini dimulai dengan menentukan stakeholder terlibat dalam SPS, tujuannya adalah untuk menentukan hal - hal yang dibutuhkan dari setiap stakeholder agar SPS berjalan. Di flowchart ini stakeholder, infrastruktur, lini interaksi antara customer dan produsen (pemilik konsep SPS), proses pendukung lainnya didefinisikan dengan jelas.

8. Rincian dana : list biaya dan modal yang dibutuhkan untuk pengembangan SPS.

\section{KESIMPULAN DAN SARAN}

Dari kajian ini dihasilkan beberapa rekomendasi :

1. Sistem produk servis masih tetap masuk dalam konteks perancangan desain karena masih menggunakan analisa permasalahan dan kebutuhan yang menjadi dasar dari pemikiran desain.

2. Enam metode SPS dikaji, dan semuanya memiliki kelebihan dan kekurangan yang masing - masing dapat saling melengkapi dalam proses desain

3. Hampir semua metode SPS yang ada saat ini harus ada landasan bisnis sebelumnya, metode yang mengkaji perancangan SPS dari awal masih belum ada.

4. Enam metode yang penting untuk dilakukan dalam proses desain SPS adalah analisa kebutuhan customer, analisa studi kasus SPS, analisa SWOT, konsep SPS, system map SPS dan rincian dana untuk realisasi SPS

Diharapkan dari studi ini dapat memperluas pengetahuan tentang bagaimana metode perancangan SPS. Kajian ini merupakan bagian dari penelitian berjudul, "Pengembangan Usaha Mikro Kecil Menengah Kriya Provinsi Banten Dengan Pendekatan Sistem Produk Servis". Kajian metode ini akan diaplikasikan dalam studi kasus perancangan pengembangan SPS untuk UMKM Kriya Banten. Diharapkan tulisan ini dapat menginspirasi perancangan SPS di Indonesia.

\section{PENGHARGAAN}

Penulis menyampaikan terima kasih kepada :

1. Elya K. Wibowo, S.Sn, MA (Art\&Design) selaku Dekan Fakultas Desain Universitas Pelita Harapan

2. Eric Jubilong, Ph.D, selaku Eksekutif Direktur LPPM Universitas Pelita Harapan

Artikel ini merupakan bagian dari Penelitian Hibah Pemula yang dibiayain oleh Direktorat Riset dan Pengabdian Masyrakat Direktorat Jendral Penguatan Riset dan Pengembangan Kementrian Riset, Teknologi dan Pendidikan Tinggi dengan No: 0419/K3/KM/2017 dan terdaftar di LPPM UPH.

\section{DAFTAR PUSTAKA}

Baines, T. S., Lightfoot, H. W., Evans, S., Neely, A.,Greenough, R., Peppard, J., . . . \& Wilson, H. (2007). Stateof- the-art in product-service systems. Journal of Engineering Manufacture, 221(10), 1543-1552. 
Bucci, A. (1992). L'impresa Guidata Dalle Idee. Milano, Domus Academy.

Butera, F. (1990). Il Castello E La Rete. Milano, Franco Angeli.

Berkowitz, M. (1987). Product shape as a design innovation strategy. Journal of Product Innovation Management,4(4), 274-283.

Bloch, P. H. (1995). Seeking the ideal form: Product design and consumer response. Journal of Marketing,59(3), 16-29.

Bouchenoire, J. L. (2003). Steering the brand in the auto industry. Design Management Journal, 14(1), 1018.

Goedkoop, M. J., Van Halen, C. J. G., Te Riele, H. R. M., \& Rommens, P. J. M. (1999). Product service systems: Ecological and economic basics. Hague, the Neherlands: Dutch Ministries of Environment (VROM). Retrieved September 30,2014, from: http://teclim.ufba.br/jsf/indicador es/holan\%20Product\%20Service \%20Systems\%20main\%20report. pdf

Manzini, E. (1993a). "Il Design Dei Servizi. La Progettazione Del Prodotto-Servizio." Design Management(4): 7-12

Manzini E., Vezzoli C. (2000). Product Service System and Sustainability. United Nations Environment Programme Publication, 4-18.

Mont, O.K., Clarifying the concept of product-service system. Journal of

Cleaner Production, 2002. 10(3): p. 237245.
Kreuzbauer, R., \& Malter, A. J. (2005). Embodied cognition and new product design: Changing product form to influence brand categorization. Journal of Product Innovation Management, 22(2), 165-176

"MePSS Webtool - Tool (Level 4)" (n.d.), MEPSS - Webtool, (accessed September 2, 2017), [available at http://www.mepss.nl/index.php?p $=$ tool $\& 14=\mathrm{W} 17]$.

Ramirez, M. (2006). Sustainability in the education of industrial designers: the case for Australia. International Journal of Sustainability in Higher Education, 7(2), 189-202.

Tukker, A. (2008). Eight types of product-service system: Eight ways to sustainability? Experiences from SusProNet. Business Strategy and the Environment, 13(4), 246-260.

Yang, X., Moore, P., Pu, J. S., \& Wong, C. B. (2009). A practical methodology for realizing product service systems for consumer products. Computers \& Industrial Engineering, 56(1), 224-235. 